\title{
Noise and temperature reduction in the contact of tribological elements during braking
}

\author{
Juraj Gerlici ${ }^{1}$, Mykola Gorbunov ${ }^{2}$, Kateryna Kravchenko ${ }^{1,{ }^{*}}$, Olga Prosvirova $^{2}$, Tomas Lack ${ }^{1}$ \\ ${ }^{1}$ Faculty of Mechanical Engineering, University of Zilina, Univerzitná 8215/1, 01026 Zilina, \\ Slovak Republic \\ ${ }^{2}$ Faculty of Transport and Logistics, Volodymyr Dahl East Ukrainian National University, \\ Central Avenue 59a, 93400 Sewerodonetsk, Ukraine
}

\begin{abstract}
This paper describes the problem of rising temperature of the friction elements during braking. Negative influence of brake pads heating on the vehicle efficiency and traffic safety is well known. Methods of temperature stabilization in the contact of tribological elements during braking are proposed. Variants of brake pad application with additional elements consisting of phase transition material are considered. Their effectiveness is estimated. The effect of the contact characteristics on noise generation is analysed. The method of noise reduction is considered. The target function for the tribological processes management in the contact of the brake elements has been developed. The application of this target function allows using the braking reserve with the achievement of maximum braking effect with minimal wear and noise.
\end{abstract}

Keywords: brake friction pair, noise generation during breaking, temperature stabilization, phase transition, target function

\section{Introduction}

Traffic safety is the key requirement when implementing new technologies in transport. Railway transport is the safest and the most energy efficient mode of transport. However, there is a problem of its use such as considerable noise, especially of freight trains at night, which negatively affects the ecological safety of the environment. Today increased noise is one of three the most harmful environmental factors. According to the EU Commission on Rail Transport, about $10 \%$ of the EU population is exposed to the harmful effects of noise from the railway transport, which is a health hazard, as well as the cause of anxiety and discomfort $[1,2]$. Therefore, if the train sound level equals $60 \mathrm{dBA}$, the percentage of population anxiety is about $10 \%$, at $75 \mathrm{dBA}-40 \%$, and at $85 \mathrm{dBA}$ the anxiety rate exceeds $70 \%$ [3].

The fight against noise is associated with serious costs: from $€ 150$ to 200 million is spent annually only to install acoustic screens along the railways in Europe. The cost of replacing metal brake pads by composite ones for freight cars can range from $€ 2$ to 2.5

\footnotetext{
*Corresponding author: kkatherina@ukr.net
}

Reviewers: Milan Sága, Alžbeta Sapietová 
billion [3].The development of new technical proposals to reduce the noise impact of the rail transport requires the identification of the main sources of noise emission.

\section{Research Analysis}

The noise produced by the rolling stock can be conditionally divided into three groups shown in Fig.1. The noise level and its distribution in the groups, percentagewise, largely depend on the speed of movement, the design of the track, the rolling stock and its elements. The noise of equipment (compressors, traction electromotors, etc.) prevails at speeds up to $50-60 \mathrm{~km} / \mathrm{h}$. Rolling noise (the collision processes in the "wheel-rail" system and the friction in the "pad-wheel" system) prevails in the speed range of $60-300 \mathrm{~km} / \mathrm{h}$. The aerodynamic noise formed by the air flow around the rolling stock hull, the pantograph, etc. prevails at speeds over $300 \mathrm{~km} / \mathrm{h}[1,2,3]$.

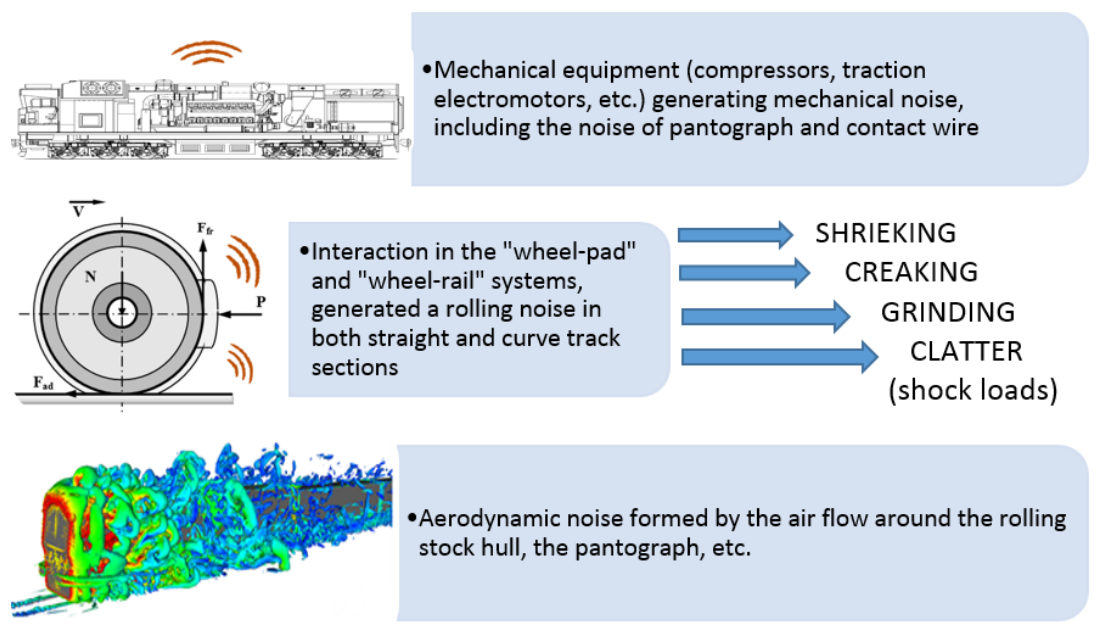

Fig. 1. Groups of noise generation by railway rolling stock operation

Despite the fact that the safety of the vehicle largely depends on the availability of an efficiently functioning braking system, its choice is the determining factor in the noise generation in the train. The results of the investigations [1-5], in which the list of train noise sources (Fig.1) and the mechanism of excitation of the main noise sources are determined, show that the reduction of the brake noise is achieved due to the stabilization of the friction coefficient (temperature) of friction bodies materials [1, 4, 5].This is due to the fact that during the braking the energy is released on friction surfaces that leads to the heating of the interacting bodies, to the structural transformations when critical temperatures are reached, to the change of the of material physical properties, and, ultimately, to the change in working conditions of friction pairs and the intensity of their wear, to the formation of defects and to an increase in noise levels. In addition, friction results in the micro-gripping of surfaces, which leads to the detachment of microparticles and the formation of squealing and creaking.

Stabilization of temperature and friction coefficient in the "wheel-pad" contact is a complex, multifactorial task, largely dependent on the conditions of interaction in the "wheel-rail" system. The pad and the rail are not interconnected constructively, however, they interact in the process of working with the same element, the wheel, and have a relationship through the loads and the physical and chemical properties of the materials. The efficiency of the "pad-wheel-rail" tribosystem, based on the properties of the materials, 
depends on their structure, which, in turn, varies depending on the heating conditions, that is, on the number and type of thermal cycles.

\section{The target function for the tribological processes management in the contact of the brake elements}

The increase in temperature in the "pad-wheel" contact and the associated adverse factors is an inevitable process. However, the use of rolling stock reserves allows temperature stabilization and prevents the formation of brake pads with critical temperatures in the tribocontact, which leads to the change in the structure of the material, and to increased wear and noise.

The reserve for the use of rolling stock is understood as follows.

In a multi-axle vehicle the maximum braking force is limited by the adhesion force of the limited, skid-prone axis, which first goes into excess slip mode, while the other wheel pairs do not reach their gripping maximums, that is, their braking capabilities, and as a result the whole vehicle capabilities are underutilized. This is due to uneven wear of wheel pairs, the difference in wheel diameters and static loads such as weight distribution, redistribution of loads from the wheel pair to the rails during braking, contact conditions, the difference of coefficients in the vertical and horizontal dynamics for each wheel pair, etc. [6, 7].The high braking force of some wheel pairs also leads to skidding, an increase in contact temperature, a decrease in safety and an increase in noise. At minimization of all unfavorable factors the reserve of braking force use by rail rolling stock will be maximum.

To estimate the braking system reserves, the target function is designed to minimize the difference between the braking force and the adhesion force of each wheel pair:

$$
C_{b}=\sum_{i=1}^{n}\left(P_{i} \varphi_{i \_ \text {max }}-B_{i} f_{i}\right) \rightarrow \min
$$

where $P_{i}$ is the vertical load from the $i$-th wheel pair to the rails, [kN], $\varphi_{i \max }$ is the coefficient of adhesion of the wheel to the rail, [dimensionless value],

$B_{i}$ is the force of pressing of a brake pad to a wheel, [kN], $f_{i}$ is the coefficient of pad friction, [dimensionless value].

The physical meaning of the target function is that, depending on the vertical load $\left(P_{i}\right)$ and the physical and mechanical properties of the "wheel-rail" contact $\left(\varphi_{i \max }\right)$, it is necessary to adjust the force of pressing the brake pads $\left(B_{i}\right)$, to stabilize the coefficient of friction in the "wheel-pad" contact $\left(f_{i}\right)$ for account of the temperature regulation in this contact.

\section{Innovative proposals for stabilizing the coefficient of friction (of temperature) in tribocontacts "wheel-rail", "wheel-pad"}

Innovative proposals for stabilizing the coefficient of friction (of temperature) in tribocontacts "wheel-rail", "wheel-pad" and the use of reserve of the braking force by a rail vehicle.

1. An effective solution for the uniform distribution of loads from wheel pairs to rails is the use of loading devices. This solution can be used not only for braking, but also for traction $[8,9]$.

2. Stabilization and increase of the adhesion coefficient is achieved due to the supply of sand into the contact of the wheel with the rail. However, sand systems work inefficiently and lead to considerable wear of surfaces. This is due to the unstable supply of sand into the contact. According to Yu.I. Osenin the maximum and sufficient amount of sand in contact 
is $0.06 \mathrm{~kg} / \mathrm{m}^{2}$ [10]. At that, the sand should lie in one layer, the distance between the particles should be regulated and equal to three radii of the sand particles. To achieve this, it is proposed to electrify the sand before it is brought into contact. This will allow to distribute the sand in one layer with the necessary distance between the grains of sand [7, $11]$.

From the theoretical and experimental studies, it has been established that the angle of sanding depends on the electric charge transferred to the abrasive mixture. The determination of the charge, depending on the design of the injectors, must be carried out according to the following system of differential equations [7]:

$$
\begin{gathered}
m_{p} \ddot{y}=-E_{\text {oy }} \cdot q_{p}+m_{p} \cdot g-R_{y}+\frac{\varepsilon_{0}(\varepsilon-1)}{2} v\left(\dot{E}_{\text {oy }}\right)^{2} \\
m_{p} \ddot{r}=-E_{\text {or }} \cdot q_{p}-R_{r}+\frac{-\varepsilon_{0}(\varepsilon-1)}{2} v\left(\dot{E}_{\text {or }}\right)^{2}
\end{gathered}
$$

where $m_{p}, q_{p}$ are the mass and charge of the abrasive particle, $E_{o y}, E_{o r}$ is the field strength for electrostatic charging, $R_{y} R_{r}$ is the resistance of air to particle motion, $\varepsilon_{o}$ is the dielectric permeability of the medium; $\varepsilon$ is the electric constant.

As a result of the simulation it was established that in order to achieve an effective sand distribution on the contact of the wheel with a rail of $60 \mathrm{~mm}$ width, the voltage applied to the charging device should be $450 \mathrm{~V}$, and the electric charge of the grains should be $1,502 \cdot 10^{-11} \mathrm{C}(15 \mathrm{pC})$.

As a result of the processing of the experimental data, the dependencies of friction coefficient from the temperature were obtained for different frictional states (Fig. 2, 3) [12]. The supply of electrified sand to oily rails makes it possible to increase the coefficient of friction in the contact from 0.25 to 0.4 (Fig. 3), to the rails covered with water from 0.35 to 0.5 (Fig. 2). Compared with the supply of non-electrified sand, the electrification effect is $16 \%$ for oily rails, $20 \%$ for water-covered rails.

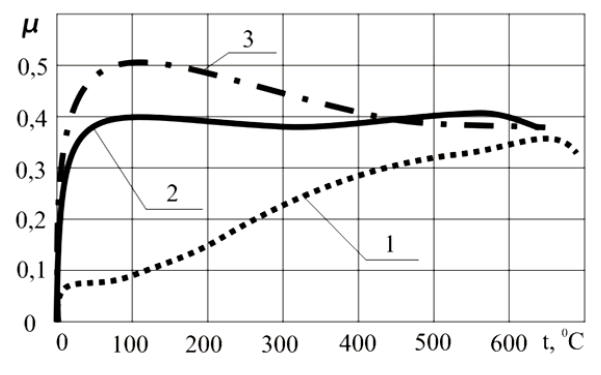

Fig. 2. The dependence of friction coefficient on temperature when supplying an electrified sand on the watered rails:

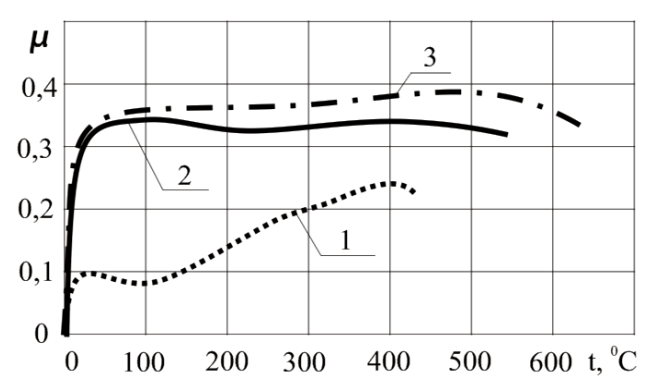

Fig. 3. The dependence of friction coefficient on temperature when supplying the electrified sand on the oiled rails:

$$
1 \text { - without sand; } 2 \text { - with sand; } 3 \text { - with electrified sand }
$$

3. It is advisable to stabilize the coefficient of friction by controlling the temperature in the contact of the wheel with the pad and removing heat from it.

An analysis of promising solutions for removing heat from the friction surface and stabilizing the temperature is carried out:

- forced air supply with the possibility of temperature control;

- the use of pads with porophore inserts;

- the use of pads with cooling fins; 
- the use of brake linings whose outer surface is made of heat-dissipating material;

- local effect of external chemical elements (ozone, foaming agents, ionized air, etc.) on tribo-elements;

- the use of inserts from materials with thermal phase transitions in the construction of the pads [13].

One of the priority methods of creating the optimum temperature regime during braking is the use of additional materials with a phase transition of the first kind in the design of brake elements. The phase state is understood as the thermodynamic equilibrium state of the substance that differs in physical properties from other possible equilibrium states of the same substance. Within one aggregate state, the substance can be in several phase states, differing in their properties, composition and structure. The transition of a substance from one phase state to another - a phase transition - is always associated with qualitative changes in the properties of the substance (changes in the aggregate state of the substance or transitions associated with changes in the composition, structure, and properties of the substance). The first-order phase transition (thermal phase transition) is accompanied by heat absorption and is characterized by a constant temperature, changes in entropy and volume. The heat supplied to the body goes not to heating the body, but to breaking the interatomic bonds.

Structurally, the brake pad with increased energy capacity contains cavities for placing materials with thermal phase transitions of the first kind. For the reason that depending on the volume of the material and the temperature of the thermal phase transition, the absorbing capacity of the heat of the pad varies, subsequently the design provides for the presence of several types of materials with phase transitions. For example, material n1 with a thermal phase transition temperature of $150-200{ }^{\circ} \mathrm{C}, n_{2}-n_{n}$ is above $200{ }^{0} \mathrm{C}$. Such solution will allow to stabilize temperatures and friction over a wide range of values.

When friction heating of the base material of the pad and reaching the temperature $T_{1}$ of the thermal phase transition of material $\zeta_{1}$, a transition occurs from one phase state to another, which is accompanied by heat absorption $Q_{1}, Q_{2}, \ldots, Q_{n}$ (Fig. 4) and temperature stabilization of the friction pair. The transition time is fixed $\left(t_{1}, t_{2}, \ldots, t_{n}\right)$ and depends on the $\zeta_{1}$ material volume. Similar processes occur with other materials of $\zeta_{n}$ inserts of the brake pad when reaching higher temperatures as shown in Fig. 4. When the train stops, the generation of heat from the friction pair also stops and a reverse phase transition occurs. By cooling the base material of the pad, the aggregate state returns to its original state.

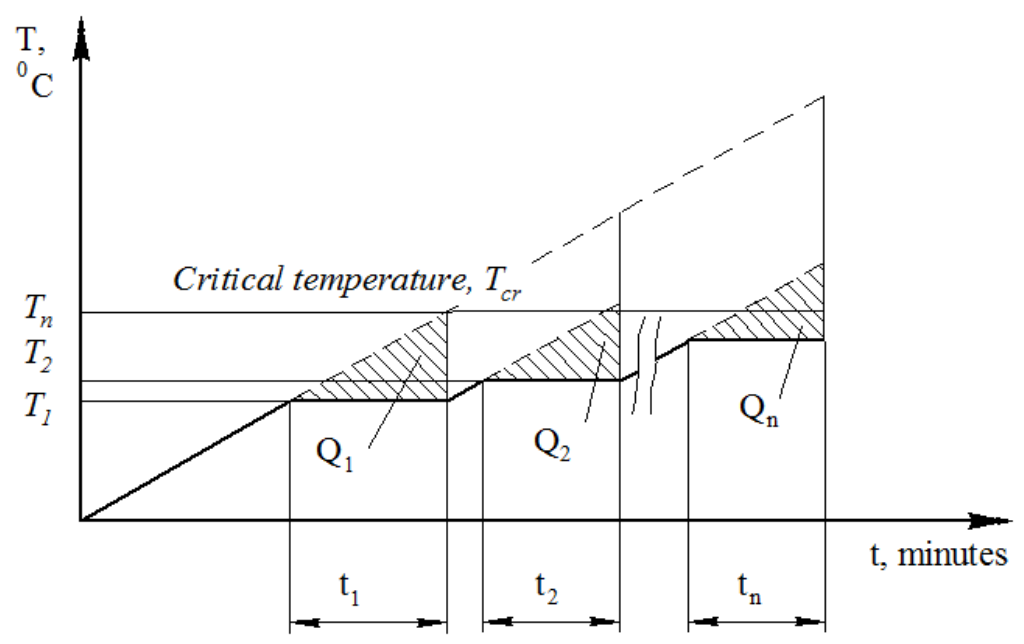

Fig. 4. Changing the brake pad temperature with increased power consumption during braking 
It can be seen from the figure that the critical temperature $T_{c r}$ of the material of the pad, which leads to deterioration of the friction parameters of the pad and to increased wear, is not achieved when using elements with a phase thermal transition, which allows to stabilize the temperature and coefficient of friction in contact, to improve the braking efficiency, to reduce wear and rolling noise level.

Stabilization of the temperature in the contact of friction pairs (wheel-rail, wheel-pad) is also provided by the supply of cooled air. When the heated friction surfaces interact with the cooled air, moisture forms on them, the so-called "self-oiling" effect. According to the studies $[6,14]$, the wet surface of the contacting surfaces reduces the coefficient of friction (Fig. 5), however, to ensure a regulated braking distance, the braking force is sufficient. At the same time, such solution significantly reduces the noise level.

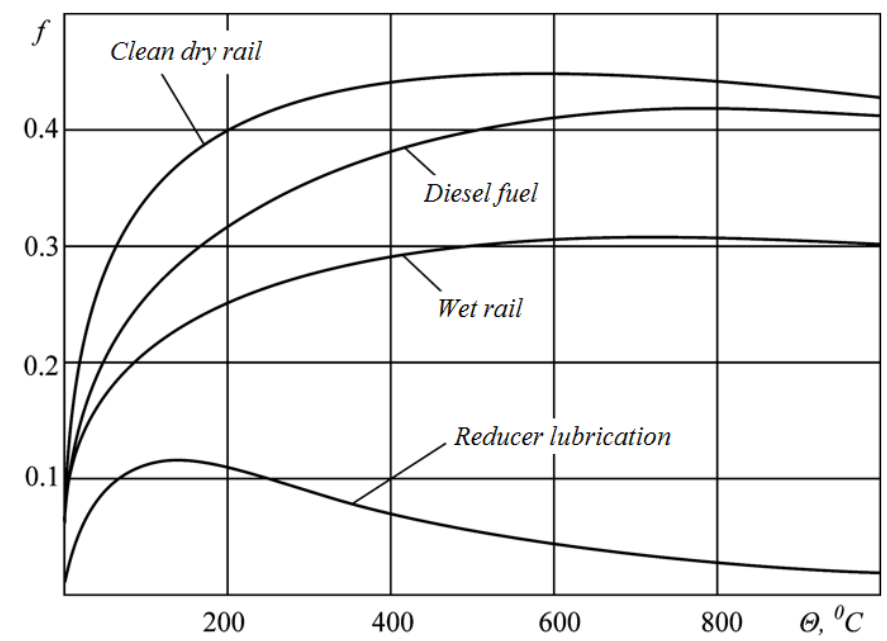

Fig. 5. Dependence of the friction coefficient on the temperature at rolling with slipping

\section{Conclusions}

Based on the analysis of promising directions for improving the brake system, innovative technical solutions and methods are proposed that consist in stabilizing the temperature and the friction coefficient of friction pairs, which ensure both an increase in braking efficiency and noise reduction. A target function has been created that makes it possible to reveal the reserves of the vehicle's braking efficiency by redistributing the forces of pressing the brake pads. The supply of electrified sand provides an increase in the stabilization of the clutch on each wheel pair.

The use of inserts from materials with thermal phase transitions in the construction of the pads provides a stable temperature (friction coefficient) in the braking process. The supply of moist air allows to stabilize the temperature and to achieve the effect of selfoiling of friction surfaces. The proposed ways of implementing the braking force reserve of the rolling stock make it possible to increase safety and to reduce the noise level from one of the noise sources - the interaction in the "pad-wheel-rail" system.

\section{References}

1. G. V. Blokland, S. Lutzenberger, Measures on Rail Traffic Noise in Europe. Input paper for the Interest Group on Traffic Noise. Abatement 4, 57 (2014) 
2. D. A. Kuklin, The problem of reducing external noise of trains at the source and along the path of expansion. dissertation abstract ... of doctor of technical Sciences: 01.04.06. Baltic state technical University VOENMECH to them. D. F. Ustinov - St. Petersburg, 52 (2016)

3. P. V. Matveev, Calculation and reduction of rolling noise of trains. dissertation ... of candidate of technical Sciences: 01.04.06. Baltic state technical University "VOENMECH". D. F. Ustinov - Saint Petersburg, 170 (2015)

4. A. R. Abu Bakar, Modelling and Simulation of Disc Brake. Contact Analysis and Squeal: Ph. D. dissertation. Liverpool (United Kingdom), 201 (2005)

5. V. I. Kolesnikov, V. P. Sergienko, S. N. Bukharov, A. P. Sychev, V. V. Sergienko, Optimization of the dynamic characteristics of friction materials and their role in noise generation under friction. Bulletin of the SOUTHERN SCIENTIFIC CENTER of RAS 5 (4), 3-14 (2009)

6. N. I. Gorbunov, Improving the traction qualities of the locomotive by improving carts elastic ties. dis. ... Ph. D.: 05.22.07 / Voroshilovgrad, 269 (1987)

7. K. A. Kravchenko, Justification the reserves for increasing the traction qualities of the locomotive and their implementation control slide in the system of wheel with a rail. dis. ... candidate of technical Sciences: 05.22.07. Lugansk 23 (2010)

8. M. I. Gorbunov, S. G. Grishchenko, V. A. Dogan, K. A. Kravchenko, S. V. Popov, A. I. Fesenko, Declaration patent for useful model No. 40369. B61C 15/00. Loading device. 18.09.2008, publ. 10.04.2009, bull. 7. (2009)

9. N. I. Gorbunov, Y. A. Kravchenko, S. G. Grishchenko, Y. Y. Osenin. Increased traction properties of the locomotive by improving the relations of the body with the trucks. Collection of scientific papers of the VIII International conference "TRIBOLOGY and RELIABILITY", Saint-Petersburg, 18-29 (2008)

10. Y. I. Attending, D. M. Marchenko, I. A. Shvedchikova, Frictional interaction of wheel with a rail. Lugansk: Publishing house of SUDU, 227 (1997)

11. M. I. Gorbunov, O. K. Kravchenko, C. B. Popov, M. V. Kovtanets, Y. Y. Osenin, Declaration patent for useful model No. 48520. B61C 15/00. A method of increasing adhesion of wheels with the rail, № u200908751, Appl. 20.08.2009 g.; publ. 25.03.2010, bull. 6 (2010)

12. N. Gorbunov, A. Kostyukevich, K. Kravchenko, Efficiency function for evaluation of the locomotive traction and adhesion qualities. TEKA Commission of Motorization and Power Industry in Agriculture X, Poland, 80-86 (2010)

13. J. Gerlici, M. Gorbunov, K. Kravchenko, O. Prosvirova, T. Lack, V. Hauser, Analysis of innovative methods for modern rolling stock brake systems efficiency increase. SBORNÍK PŘÍSPĚVKŮ Z mezinárodní vědecké konference pro mladé vědecké pracovníky "Experimentální a výpočtové metody v inženýrství" Usti nad Labem, Czech Republic, electronic publishing (2017)

14. A. L. Golubenko, Adhesion of wheel and rail. 2nd edit.- Lugansk: VUGU, 476 (1999) 